\title{
Entrevistarte: Experiência, Arte e Contemporaneidade
}

Entrevistarte: Experience, Art and Contemporaneity

Entrevistarte: Experiência, Arte y Contemporaneidad

\begin{abstract}
Lilian Hack
Universidade Federal do Rio Grande do Sul, Porto Alegre, RS, Brasil.

Édio Raniere

Universidade Federal do Rio Grande do Sul, Porto Alegre, RS, Brasil.
\end{abstract}

\section{Cleci Maraschin}

Universidade Federal do Rio Grande do Sul, Porto Alegre, RS, Brasil.

\begin{abstract}
Resumo
$\mathrm{O}$ artigo explora ressonâncias entre arte e psicologia. Em métodos tradicionais de pesquisa a entrevista com artistas aparece, quase sempre, como fonte primária de informação. Nesses a explicação da obra torna-se o grande objetivo do pesquisador. Ao artista restaria um saber implícito, desgovernado, e por vezes incoerente sobre aquilo que ele mesmo criou. Saber que seria desvelado, explicitado, revelado pelo crítico/pesquisador. A aposta deste trabalho é de que a Entrevista de Explicitação, técnica desenvolvida pelo psicólogo francês Pierre Vermesch, seja uma importante contribuição, nesse sentido, às pesquisas em arte. Afinal, o que aconteceria se à entrevista coubesse cartografar o processo de criação, ou se, em meio às investigações, o crítico mantivesse sua escuta atenta ao Know How - saber como - enunciado pelo artista? Numa tentativa de aprofundar a problematização recorre-se a conceitos de Thierry De Duve, Varela, Thompson e Rosch, bem como dos artistas Allan Kaprow e Robert Smithson.
\end{abstract}

Palavras Chave: Arte; Psicologia; Método; Entrevista de explicitação; Entrevista com artistas

\begin{abstract}
The article explores resonances between art and psychology. In traditional research methods, interviews with artists appears almost always as a primary source of information. In those, the explanation of the work becomes the main objective of the researcher. To the artist would remain an implicit knowledge, ungoverned, and at times incoherent, about his own creation. Knowledge that would be unveiled, made explicit, revealed by the critic/researcher. The present work propose that the Explicitation Interviewing, a technique developed by the French psychologist Pierre Vermesch, is an important contribution in this sense, to the art research. After all, what would happen if through the interview we could map the process of creation? Or, in the
\end{abstract}


midst of investigations, the critic could keep his listening tuned to the Know How enunciated by the artist? In an attempt to deepen these questions, we refer to concepts of Thierry De Duve, Varela, Thompson and Rosch, as well as artists like Allan Kaprow and Robert Smithson.

Key Words: Art, Psychology, Method, Interview specification; Interview with artists

\section{Resumen}

El artículo explora las resonancias entre arte y psicología. En los métodos tradicionales de investigación la entrevista con artistas es considerada casi siempre una fuente primaria de información. La búsqueda por la explicación de la obra por parte del artista se convierte en uno de los grandes objetivos de muchas investigaciones. Uno considera que el artista tiene un conocimiento implícito, en fuga y, a veces inconsciente, acerca de lo que él mismo creó. Sería tarea del crítico/investigador desvelar y explicar ese conocimiento. Este artículo propone que la entrevista de explicación, una técnica desarrollada por el psicólogo francés Pierre Vermesch, trae importante contribución a la investigación en el campo del arte. Después de todo, ¿qué pasaría si con la entrevista deseamos seguir el proceso de creación del artista, o si, en medio al trabajo el investigador mantuviera su escucha atenta para el Know How - saber hacer - declarado por el artista? Con el intento de profundizar ese cuestionamiento agregamos conceptos de Thierry De Duve, Varela, Thompson y Rosch y de artistas como Allan Kaprow y Robert Smithson.

Palabras clave: Arte, Psicología, Método de especificación; Entrevista de explicitud; Entrevista a los artistas

Quando se pesquisa arte, seja uma obra em específico e/ou o conjunto de obras de um artista, o que se pode, e o que se quer conhecer? Nos trabalhos do biólogo chileno Francisco Varela encontra-se uma importante análise sobre produção de conhecimento. Varela problematiza o conhecimento dividindo-o em Know What - saber o que - e Know How - saber fazer. Sendo uma de suas principais criticas o excesso de valorização dada pelas ciências ao Know What.
Boa parte do legado deixado por Varela destina-se a abrir as pesquisas científicas ao Know How. Aproximar as ciências do saber fazer. Estranho, contudo, é reconhecer que mesmo nas artes muitas pesquisas acadêmicas, ainda hoje, continuam agenciadas quase que exclusivamente pelo Know What. Aqui um paradoxo se apresenta: a experiência que um crítico encontra em uma obra está atravessada predominante por significações e não por fazeres; característica que empres- 
ta a sua voz uma excelente narrativa sobre o que aquela obra é, pretende, explora, etc. Já a experiência que um artista encontra em sua própria obra tende muito mais às ações. Mesmo num trabalho conceitual, onde por vezes a própria obra consiste em ideias, que se fazem apresentar por diferentes meios (intervenção, instalação, performance, etc.), há um fazer envolvido, não para explicar essa ideia, mas para dispará-la, lançá-la à obra. Trata-se, portanto, de um saber inventivo em contraponto a um saber explicativo.

Para muitos, porém, mais do que um limite analítico trata-se objetivamente de um lugar a ser ocupado. Ou seja, a função da crítica em artes seria justamente traduzir, explicar, explicitar a obra. Nas palavras de Thierry De Duve, reconhecido como importante crítico da contemporaneidade: "Meu trabalho está situado dentro das fronteiras de uma prática que busca explicação, não invenção, nem poesia ou arte. Minha tarefa é desenterrar e tornar explicito o pensamento teórico que nela [na obra] segue implicitamente.” (2004, p. 36)

Assim, enquanto o conhecimento do crítico vem atravessado pelo o que a obra é, o saber de um artista aparece acoplado ao processo, à ação, a uma espécie de work in progress infinito. Não é à toa que ao serem convocados a significações - o que isso quer dizer? - de suas obras muitos artistas tenham dificuldades de explicitá-las. Aqui- lo que ele sabe não passa necessariamente pelo o que a obra significa, mas antes pelo acontecimento que a obra fabrica. Ela compõe uma série de investigações para o artista. Investigações conceituais, materiais, de acoplamento, de relação.

Seria possível ultrapassar essa barreira que separa a crítica da obra do processo experimentado pelo artista, ou mesmo ainda, pelo público? Acreditamos que sim. Vamos seguir uma pista deixada pelo próprio Thierry De Duve: “O pior engano, para um crítico, é acreditar que se pode colocar o ponto de vista de um artista à disposição entrevistando-o." (2004, pp. 44-45) Nossa hipótese, neste sentido, aproxima-se do que o crítico sugere, de que o ponto de vista que o artista detém a respeito de sua obra é menos relevante que o processo acionado por ele ao construir uma obra, e neste sentido, desejamos dar um passo adiante. Dizendo de outra forma, o que aconteceria se a técnica da entrevista fosse utilizada para cartografar o processo e não para explicar a obra? O que aconteceria se, nessa investigação, o crítico mantivesse sua escuta atenta ao Know How e não ao Know What enunciado pelo artista?

Numa tentativa de aprofundar esta discussão vamos recorrer ao pensamento de Franscisco Varela e Pierre Vermesch. Nossa intenção, de maneira geral é problematizar a experiência na arte abrindo-a para um modo particular de pesquisa. 
Trata-se de uma investigação que quer explorar não as significações atribuídas à arte, o saber o que, e as interpretações que daí decorrem; mas o próprio fazer, o como desse fazer. Para além meramente dos procedimentos, o processo. Para extrair destas investigações não respostas, mas antes um pensamento, um modo de pensar que a arte pode provocar, e que o artista, como aquele que possui esse encontro e entrelaçamento mais dilatado em nossa sociedade, pode experimentar ${ }^{1}$.

Dessa forma dividiremos este ensaio em dois momentos. Primeiro investigaremos algumas questões acerca da experiência, expostas por Varela, Thompson e Rosch em A mente incorporada: ciências cognitivas e experiência humana (1991), e em um segundo momento, partindo destas perspectivas, desenvolveremos uma proposta de análise dos estudos de Vermesch acerca de L'entretien d'explicitation (1994).

\section{Experiência e mente incorporada}

Qual a relação da experiência com a arte? Quando começa e termina uma experiência artística? Como se processa essa experiência?

Em A mente incorporada: ciências cognitivas e experiência humana (1991), Varela, Thompson e Rosch, exploram um campo que procura encontrar pontos de Rev. Polis e Psique, 2013; 3(2):113-131 confluência entre diversas disciplinas para pensar a experiência. Partindo da fenomenologia, especialmente aquela legada por Merleau-Ponty, e em certos aspectos também por Heidegger, os autores procuram aportes na filosofia, entrelaçando a mesma às pesquisas desenvolvidas na psicologia, neurologia, biologia, e, sobretudo nas ciências cognitivas, que abrigam outras perspectivas além da corrente mais propalada do cognitivismo ${ }^{2}$. Neste ponto os autores também elaboram uma crítica ao pensamento ocidental, no que tange às investigações acerca da experiência, argumentando que mesmo os filósofos que problematizam essa questão, criticando a centralidade do racionalismo científico, "o fazem somente por meio de argumentos, demonstrações e exibições linguísticas, ou seja, por meio do pensamento abstrato." (1991, p. 37) É sob esta perspectiva que os autores procuram por convergências, por novas possibilidades de pensar a experiência humana, propondo um passo audacioso em direção à filosofia não ocidental, especialmente ao pensamento indiano, ligado à filosofia budista ${ }^{3}$ :

Se a filosofia ocidental não ocupa mais uma posição privilegiada e fundacional no que diz respeito a outras atividades culturais como a ciência ou a arte, então uma completa apreciação da filosofia e de sua importância para a experiência humana exige que examinemos o papel da filosofia em culturas diferentes da nossa. (1991, p. 38) 
Mais que isso, talvez a experiência, tomada como conceito, não seja mais possível ao pensamento ocidental. Talvez a junção realizada por Descartes entre o sujeito da experiência e o sujeito da ciência - o nôus que até então era impassível, divino - tenha atingido seu limite. Para o filósofo italiano Giorgio Agamben,

a questão da experiência pode ser abordada nos dias de hoje apenas com a confirmação de que ela não é mais acessível a nós. Pois, assim como o homem moderno foi privado de sua biografia, sua experiência foi igualmente expropriada. De fato, sua incapacidade de ter e comunicar experiências é talvez uma das poucas certezas que ele pode reivindicar. (2005, p.7)

De uma forma ou de outra o que importa aos autores de $A$ mente Incorporda parece ser buscar possibilidades a este agenciamento perdido. Nesse sentido recorrem à tradição filosófica budista, mais especificamente a apresentada pela filosofia Madhyamika (que significa caminho do meio), a qual aproximam do conceito de entre-deux, explorado por Merleau-Ponty, e às ideias de cognição como atuação (em oposição à lógica representacional do cognitivismo). A razão deste interesse está principalmente em investigar o método budista de meditação atenta, que possibilitaria um exame da experiência não a partir de investigações teóricas e abstratas, como a tradição filosófica ocidental. Para a tradição indiana, "a filosofia nunca se tornou uma ocupação puramente abstrata" (1991, p. 39), ela estaria sempre ligada (yoked), a métodos disciplinares específicos de conhecimento, ou seja, a diferentes métodos de meditação, e em especial, ao método de atenção/consciência, sobre o qual os autores se debruçam em sua pesquisa. Nessa perspectiva atenção significa que “a mente está presente na experiência incorporada de cada dia", e as técnicas de atenção seriam "projetadas para levar a mente de volta de suas teorias e preocupações - da atitude abstrata -, para a situação da própria experiência da pessoa.” (1991, p. 39) Para os autores, em nossa cultura as investigações acerca da relação entre mente e corpo são paralisadas por concepções meramente conceituais, ou abstratas. A reflexão, segundo observam, "é tida como estritamente mental, e assim surge o problema de como ela poderia estar ligada à vida corporal." (1991, p. 46)

É importante ressaltar que os autores preocupam-se com a relação entre pesquisa científica e budismo. $\mathrm{O}$ fato de que no ocidente o budismo é frequentemente reconhecido como religião, os levam a considerar que "a designação e o delineamento do que seja 'religião' no ocidente é por si só um artefato cultural que pode, se tomado ao pé da letra, dificultar seriamente nossa compreensão de outras tradições.” (1991, 
p. 39) Além disso, segundo os autores, as práticas budistas não compõe uma tradição estagnada, que remete a um outro período histórico, mas se tratam de uma "tradição viva", praticada inclusive fora do sudeste asiático, em países das Américas e da Europa, onde diversas formas de ensinamento são perpetradas. Justificam ainda o grande interesse no desenvolvimento de pesquisas nesse sentido, já que os estudos contemporâneos do budismo interessam não apenas a seus praticantes, mas aos pesquisadores e intelectuais em geral, das ciências humanas e cognitivas, por exemplo.

O objetivo da prática budista de atenção/consciência, segundo os autores, “é levar a pessoa a tornar-se atenta, experienciar o que a mente está fazendo enquanto ela o faz, estar junto com a própria mente." (1991, p. 40) Se mente e corpo não estão em coordenação, no sentido budista, não se estaria presente. A finalidade da meditação, portanto, não seria promover um estado de relaxamento absorto, mas antes de presença, onde é possível "tornar a mente capaz de estar presente em si mesma o tempo suficiente para obter insights sobre sua própria natureza e funcionamento.” (1991, p. 41) A dissociação entre mente e corpo, entre consciência e experiência, seria o resultado de um hábito, que poderia ser transformado através da meditação de atenção/consciência.
Assim a atitude abstrata que Heidegger e Merleau-Ponty atribuem à ciência e à filosofia, seria na realidade, a atitude da vida cotidiana quando não estaríamos atentos, presentes: "essa atitude é o traje espacial, o acolchoamento feito de hábitos e pressuposições, a armadura com a qual uma pessoa habitualmente se distancia de sua experiência." (1991, p. 42) A mente inquieta estaria sempre procurando se agarrar a pontos estáveis em seu movimento sem fim, "apegar-se a pensamentos, sentimentos e conceitos como se eles fossem uma base sólida." (1991, p. 42) À medida que todos esses hábitos seriam eliminados através das técnicas de meditação de atenção/consciência, a possibilidade de refletir sobre sua própria experiência seria salientada.

\section{Experiência e reflexão incorporada e arte}

Poderíamos encontrar na arte uma oposição a essa atitude abstrata? O processo artístico é agenciado simultaneamente por saberes que se fazem e fazeres que se sabem, por estados de observação, de experimentação conceitual, assim como de elaboração material, os quais acionam no corpo artístico uma presença encarnada, incorporada, onde a reflexão se constitui no próprio campo sobre o qual o artista elabora sua prática. Tal reflexão não poderia também 
ser acionada pelo público ao se relacionar com uma obra?

Vejamos o que Varela, Thompson e Rosch, para quem a reflexão possui um papel fundamental na prática de meditação de atenção/consciência, propõem sobre a função da reflexão, e como ela se desenvolve nestas asserções.

O que os autores sugerem é uma mudança na natureza da reflexão, ou seja, de uma atividade abstrata, desincorporada, ela passaria a uma atividade incorporada (atenta, presente) e aberta. Por incorporada os autores se referem a uma reflexão em que "mente e corpo foram unidos", e o que essa formulação pretende veicular é que "a reflexão não é apenas sobre a experiência, mas ela própria é uma forma de experiência." (1991, p. 43) Para os pesquisadores, quando a reflexão é feita dessa forma ela poderia interromper ou quebrar a cadeia de padrões de pensamentos habituais e preconcepções, de forma a ser uma reflexão aberta: "aberta a possibilidades diferentes daquelas contidas nas representações comuns que uma pessoa tem do espaço da vida.” (1991, p. 43)

De certa forma podemos aproximar essa concepção acerca da reflexão incorporada dos processos artísticos. Não seria essa justamente a potência da arte, interromper e quebrar categorias habituais de relação com o mundo, com os objetos? Especialmente na arte contemporânea o que vemos é uma constante apropriação dos objetos cotidianos, das relações e hábitos cotidianos, para fabricar com eles uma quebra de suas representações comuns, para abrir concepções acerca do espaço existencial. Como uma imagem desse exercício da arte podemos citar as palavras da artista brasileira Adriana Varejão:

$$
\begin{aligned}
& \text { Eu costumo sempre me lembrar dessa } \\
& \text { imagem das minhocas. Os artistas como } \\
& \text { minhocas que arejam a linguagem. E se } \\
& \text { eu fosse definir uma ideia do que é arte, } \\
& \text { é propor um arejamento da linguagem, } \\
& \text { ou seja, tirar a linguagem do mundo, } \\
& \text { tirar as coisas do mundo que a gente está } \\
& \text { acostumado a colocar elas. A gente dá uma } \\
& \text { função às coisas, à tudo, a gente deixa de } \\
& \text { ver muita coisa por causa disso, por só ver a } \\
& \text { função que as coisas tem, e devolver elas a } \\
& \text { um outro universo que é mais onírico, a um } \\
& \text { universo relacionado ao mundo dos sonhos. }
\end{aligned}
$$
(2012)

A pergunta comum que impulsiona o pensamento ocidental seja nas práticas de cientistas ou de filósofos, segundo Varela, tem sempre sua referência no know what: "o que é a mente?”, “o que é o corpo?”, etc. Mas a deficiência principal causada por esse impulso de pesquisa seria prosseguir refletindo apenas conceitualmente, ou seja, cientificamente ou teoricamente, dando origem a experimentos, afirmações e resultados que não levam em conta quem está fazendo a pergunta e como ela está sendo feita: “por 
não nos incluirmos na reflexão, fazemos apenas uma reflexão parcial, e nossa pergunta torna-se desincorporada." (1991, p. 44, grifo nosso)

Segundo os autores é, portanto, uma questão de simples hábito nossa mente e corpo poderem ser dissociados, a mente poder divagar, podermos não estar conscientes sobre nosso corpo e sobre o que nosso corpo ou mente estão fazendo. Esse hábito da falta de atenção pode assim ser transformado através de técnicas que procurem coordenar a ambos, como já apontamos.

Conforme os próprios autores assinalam, tipicamente na cultura ocidental, essa habilidade de coordenar mente e corpo na reflexão, essa atenção ou presença a que se referem, seria associada às ações de um especialista, como um atleta ou um músico, e para ampliarmos essa discussão, poderíamos inferir, como um artista. Não estaria aqui o reconhecimento destes autores de que, na cultura ocidental, a arte também é atravessada por essa potência?

No entanto, na verdade, o argumento dos pesquisadores caminha para uma hierarquização entre o que chamam de habilidade artística e de meditação atenta/ consciente. Para eles haveria "duas formas de se falar sobre o desenvolvimento da reflexão incorporada", uma das formas, a qual aproximam de uma abordagem preliminar, ou de iniciante, seria o desenvolvimento de uma habilidade, comparada ao aprendizado de um instrumento musical - como a flauta - ou seja, ao desenvolvimento de habilidades artísticas. Mas os autores ponderam que apenas desenvolver essa habilidade, como um virtuose, por exemplo, não permitiria alcançar essa atenção ao presente. Ficar restrito ao desenvolvimento de habilidades especiais, um virtuosismo de técnicas, levaria à direção oposta, e a um processo de auto-ilusão. A segunda forma, portanto, como podemos compreender, seria trabalhar sobre as práticas de meditação da atenção/consciência no sentido de praticar o abandono de hábitos de desatenção durante a experiência, num esforço que seria diferente daquele em que se busca aprender algo novo. Portanto, trata-se de procurar por um desaprendizado que preconiza uma abertura a um esvaziamento da mente, para enfim atingir uma percepção atenta da experiência. Haveria sim uma técnica envolvida para se atingir essa percepção, uma habilidade necessária, mas ela não seria vista como um exercício de aprendizado, e sim, antes, como um estado de leveza e fluidez atenta sobre a experiência.

Na comparação realizada pelos autores, se tomarmos a primeira modalidade de desenvolvimento da atenção incorporada, poderíamos afirmar que esta se trata de uma arte atrelada puramente à técnica, a questões formais. Concordamos, nesse sentido, 
que esta arte que quer desenvolver apenas habilidades estaria, hierarquicamente falando, abaixo da meditação em se tratando da presença atenta.

Ou seja, se o sujeito abordar a técnica de meditação como o mero desenvolvimento de uma habilidade "sua mente se fixa e se acelera, e a atenção/consciência é mais evasiva.” (p. 45) Assim fica claro que é o modo de abordar a meditação que implica sua experiência. Podemos admitir o mesmo acerca da arte. Se a tomarmos como mero desenvolvimento de técnicas a estaremos abordando pura e simplesmente por meios formais, como o desenvolvimento de uma habilidade. Contudo, muitos são os exemplos, especialmente na arte contemporânea, que fogem disso. Não se trata de meramente desenvolver uma habilidade, mas antes de encontrar na arte um meio, um modo de fabricar acoplamentos, agenciamentos com o mundo, através, também, de uma perspectiva em que a experiência envolva presença e atenção.

O que propomos, portanto, não é necessariamente seguir estes passos guiados por perspectivas que apontem à filosofia budista para propor novos modos de pensar $\mathrm{a}$ arte, porque acreditamos que de certa forma estas entradas, ou influências, já estejam formuladas pelo pensamento artístico contemporâneo.

Rev. Polis e Psique, 2013;3(2):113-131
Tão somente para darmos um exemplo ao que desejamos explicitar trazemos Allan Kaprow, artista reconhecido como um dos precursores do happening, ou da performance, que em um texto famoso escrito em homenagem ao pintor Jackson Pollock, nos diz o seguinte, acerca da experiência provocada pela relação com a obra deste artista:

Prazer igual ao da participação em um delírio, um aniquilamento das faculdades da razão, uma perda do self, no sentido ocidental do termo. Essa estranha combinação de extrema individualidade e ausência de si (selflessness) torna a obra extraordinariamente potente, mas também indica uma estrutura provavelmente mais ampla de referências psicológicas. (2009, p. 42)

Vemos aí, de modo sutil, algo do legado desse pensamento oriental (selflessness), como o que aponta Varela, no que tange a esse esvaziamento da mente, de que falávamos anteriormente. Esvaziamento que apareceria aqui na experiência do pintor, assim como do observador - o próprio Kaprow nesse caso.

Nas diferentes produções que pululam no contemporâneo, fica cada vez mais evidente que trabalhar com arte não implica, necessariamente, o mero desenvolvimento de uma habilidade, mas antes de um incessante questionamento do mundo, questionamento do objeto, daquilo que é tomado 
como comum e habitual. Habitual que impulsiona também a pesquisa de Varela sobre as técnicas de meditação de atenção/consciência. A arte, cada vez mais, produz interrogações sobre o modo como vivemos, como nos relacionamos com os objetos (seja uma pedra, um punhado de terra, um vaso ou o computador), como nos relacionamos uns com os outros. Mais do que uma habilidade, trata-se de uma observação arguta do que está diante dos olhos, dos quadriculados filosóficos, políticos, sociais e institucionais, para promover espécies de transvalorações, transbordamentos de significados.

Para engrossarmos esse caldo, podemos citar alguns artistas. Um primeiro exemplo nos leva ao americano Robert Smithson, cujos trabalhos, conhecidos como Land Art, e ainda como o que chamava de non-sites, apontam para alguns entrelaçamentos da arte com a ciência, antes como um questionamento de ambas em seu confronto, o que o ajuda a problematizar a experiência: "Escrevi recentemente um artigo chamado Strata: a geophotografic ficcion, que cobre desde o período Pré-Cambriano até o Cretáceo. Lidei com isso como sendo uma ficção. A ciência funciona, é verdade. Mas com que objetivo? Remexer a poeira da lua com milhões de dólares. Estou mais interessado em todos os aspectos do tempo. E também na experiência que você conquista no site, quando se confronta com o Rev. Polis e Psique, 2013; 3(2):113-131 aspecto físico da duração real. Tome como exemplo o non-site Palisades: você vai encontrar rastros de roldanas enterrados no chão, vestígios de outras coisas mais. Toda tecnologia é matéria construída sob a forma de estruturas ideais. A ciência é uma choupana no meio do fluxo de lava das ideias. Tudo deve voltar para a poeira. A poeira da lua, talvez. (2009, p. 284)

Marina Abramovic, artista iugoslava, também reconhecida como uma das precursoras da performance, tem produzido trabalhos que cada vez mais procuram propor ao espectador uma experiência, que extrapole a relação com o objeto. Em suas palavras,

o grande princípio da arte é que ela é uma ferramenta. Se arte é algo que só trata de um objeto, ela perde sua função. A arte tem que ser uma ferramenta para conectar ou questionar." Para Abramovic, ainda "os objetos, eles mesmos, não tem valor. Quem tem valor é o processo e quando você passa por uma experiência, existe a transformação. (2013)

No caso de trabalhos mais recentes, como sua exposição The Artist is Present, no MoMa de Nova York, sua própria presença transforma-se em obra. A respeito desse trabalho, a artista fala em entrevista dada à Folha de São Paulo:

A exposição no MoMA foi uma retrospectiva de tudo que já fiz e, ao mesmo tempo, uma 
nova performance. No começo havia duas cadeiras e uma mesa e, no final, decidi tirar a mesa e ficaram só as cadeiras. A performance durou três meses e, após tanto tempo, ela criou vida própria. E eu comecei a pensar em tantas coisas da minha vida, e, você sabe, a gente faz tanta merda em nossa vida, estamos cercados por tantos conceitos, tantos projetos e coisas desnecessárias, coisas que a gente coleciona, coisas que a gente quer, que eu realmente senti uma imensa necessidade de voltar à natureza, isso é, retornar a uma certa ritualização do cotidiano, como aproveitar o ato de beber um copo de água, segurar uma ovelha. (2013)

Talvez possamos apenas nos perguntar se em nossa relação com a arte temos nos permitido experimentar tão pouco, ou de maneira precipitada, e assim também formulado estas experiências de modo rudimentar e imediato, procurando apenas pelos significados da obra, e não por nos colocarmos presentes na experiência, atentos também à reflexão que ela provoca. E isto não apenas através da obra pronta, acabada e exposta em um museu ou galeria, mas também através dos procedimentos de invenção, de criação da mesma, atentos ao processo, mais do que ao resultado, em procedimentos parecidos com os que levam Varela a questionar o pensamento ocidental sobre a experiência, indo buscar respostas a isso na filosofia oriental.
$\mathrm{O}$ que restaria seria pensar como podemos investigar a arte que se produz hoje através dessa ótica proposta por Varela, procurando pensar a experiência através de uma perspectiva em que a reflexão seja incorporada, levando em conta o presente, uma atenção ao presente, produzindo conhecimento em uma perspectiva integrada, a partir do know how - do processo - ao invés apenas do know what - do que significa a arte, a obra. Compreendendo que a produção de significado não deixa de ocorrer, mas ela está atrelada à experiência da mente incorporada, à experiência produzida a partir do ponto de vista de quem a produz, e de como ela é produzida. Onde os significados se dão, como podemos sugerir, a partir de invenções, de fabulações, que transcorrem na contramão de um pensamento fundacional, ou racionalista, que quer apenas interpretar ou explicar.

\section{Entrevistarte}

Podemos agora considerar o método de Vermesch, como já anunciamos anteriormente, para pensar uma proposta de investigação da experiência na arte. O que desejamos propor através desse percurso de pesquisa, portanto, não estaria atrelado de forma estrita aos procedimentos utilizados por Vermesch, mas antes tomaria suas investigações como um impulso, um dispara- 
dor a uma abordagem de entrevista que visa explorar a experiência na arte, onde esta primeiramente se configura, ou seja, nos processos desenvolvidos pelo artista. Portanto, em um primeiro momento, o sujeito que nos interessa entrevistar é o artista.

Por muito tempo a entrevista com artistas fora tomada como fonte primária de informação. Ao crítico caberia fundamentar sua análise sobre esta, entre outras fontes. Já que se creditava ao artista um saber implícito sobre a obra. Saber que seria desvelado, explicado, explicitado pelo crítico. Mais uma vez o que sempre se procurou realizar através da entrevista parece estar atrelado apenas ao Know What. Como nossa intenção é utilizar a entrevista para abrir o processo de criação, e não seu significado, tentaremos nos aproximar do Know How. Neste sentido é que desejamos recorrer às pesquisas de Pierre Vermesch.

Em L'entretien d'explicitation, este psicólogo francês compartilha vários anos de pesquisa a respeito do que ele nomina Entrevista de Explicitação:

Um dos grandes fascínios que exerce sobre mim, ainda hoje, a entrevista de explicitação: questionar uma pessoa que começa pela afirmação de não saber como ela fez ou o que se passou (portanto subjetivamente não-consciente para ela) e ouvi-la descrever progressivamente, com precisão, suas ações à medida que a entrevista progride, descobrindo simultaneamente (ela e eu) os detalhes de sua vivência. Pois é bem isso que vai se operar com a entrevista de explicitação: a verbalização da vivência da ação vai se fazer através de uma tomada de consciência provocada por elementos cujo sujeito não sabe ainda que os conhece e até mesmo crê saber que não os conhece. (Vermesch, 1994, p.3)

Vermesch resume a Entrevista de Explicitação como uma técnica, a qual permitiria objetivar expressões verbais acopladas a domínios particulares da experiência. Sendo que o conjunto de práticas que resultariam desta técnica seria acionado por meio de formulações que ele chama de relances. Ou seja, questões, reformulações, silêncios - abertos a partir da escuta.

Assim, a Entrevista de Explicitação, ao explorar o desenvolvimento de uma determinada ação, possibilita descrever a maneira como efetivamente esta ação foi colocada em prática numa tarefa concreta. Por meio da descrição desse desenvolvimento, e não apenas do resultado final de uma ação, Vermesch orienta seus alunos. A utilização pedagógica da Entrevista de Explicitação serve, portanto, para que o aluno perceba como suas ações se relacionam com o processo de sua aprendizagem.

Nossa hipótese é de que a mesma estratégia possa ser utilizada para pensar não apenas o resultado final - a obra - mas o processo de criação, o desenvolvimento de 
uma determinada ação efetuada por um artista. Obviamente, seria necessário deslocar o carácter pedagógico da Entrevista de Explicitação a uma dimensão artístico exploratória.

Mas como se daria isso na prática? Como realizar uma Entrevista de Explicitação com um artista? Quais os principais pontos a serem levados em conta?

Tentaremos agora resumir em cinco etapas, o que nos parecem os principais momentos apontados por Vermesch em L'entretien d'explicitation, deslocando nelas a função puramente pedagógica e ao mesmo tempo aproximando-as de uma pesquisa em arte:

\section{Prólogo: tempo}

A Entrevista de Explicitação pretende trazer à descrição uma experiência ocorrida em um determinado tempo, que iremos chamar de T1. Ao vivenciar esta experiência o corpo do artista está entregue a um processo, à ação, à invenção de uma obra. T1, portanto, é um momento de experiência do artista, em que se realiza uma ação. Numa segunda temporalidade, que chamaremos de T2, o foco deixa de ser propriamente a construção da obra e passa a ser a evocação e a descrição das ações que a construíram, o processo. T2 é também uma experiência, trata-se do momento em que o artista des- creve a ação, o processo, vivenciado em T1. Para que o artista possa em T2 encontrar as ações realizadas em T1 torna-se fundamental a mediação do entrevistador. Portanto, para trazer à tona este momento, se configura a proposta de entrevista que aqui exploramos. Cabe ao entrevistador direcionar o artista a esse encontro levando sempre a descrição para a ação efetiva. Nesse momento abre-se um terceiro nível, que vamos chamar de T3. Ou seja, trata-se da possibilidade de refletir sobre T2, espécie de reflexão da reflexão, de perceber se a fala do artista descreve ou não T1. O procedimento que envolve T3 parte do mediador, que dispõe dos conceitos para disparar essa reflexão. Contudo, esse movimento não é exclusivo do mediador, ocorrendo num entre-deux, num acoplamento entre entrevistador e entrevistado.

Cabe aqui uma pequena ressalva. Para Vermesh a ação que envolve T2 é uma experiência de rememoração. O que o sujeito experimenta é uma espécie de retorno a uma realidade já vivida. Acreditamos, contudo, que aqui também se trata de um processo inventivo, ou seja, para além de uma descrição representativa, para além de uma narrativa que pretende recuperar uma verdade, o que se produz em T2 é uma experiência tão inventiva quanto a que se produziu em T1. Nas palavras de Bergson: “Em se tratando da lembrança, o corpo conserva 
hábitos motores capazes de desempenhar de novo o passado; pode retomar atitudes em que o passado irá se inserir; ou ainda, pela repetição de certos fenômenos cerebrais que prolongaram antigas percepções, irá fornecer à lembrança um ponto de ligação com o atual, um meio de reconquistar na realidade presente uma influência perdida: mas em nenhum caso o cérebro armazenará lembranças ou imagens.” (1990, p.185)

Ou seja, nossas lembranças não ficam armazenadas em gavetas cerebrais, as quais se poderiam, através de técnicas bem aplicadas, acessar, abrir, extrair. Este passado - virtual - necessita de uma nova experiência para ser atualizado. Entretanto esta ação, que ocorre justamente no atual, seria sempre uma nova experiência.

\section{Primeiro ato: contrato}

Antes de mais nada o artista deve ser informado do que será realizado. O contrato inicia a Entrevista e a ele sempre se pode recorrer em momentos de interrupção, constrangimento, insegurança. Um bom contrato é aquele que ao mesmo tempo permite o encontro do artista com a fala encarnada e o deixa livre para escolher continuar ou não sua narrativa. Se o artista manifestar verbal ou fisicamente um desconforto é hora de refazer o contrato. O mais importante é deixar claro o papel de cada um na entrevista, bem como o objetivo da mesma, o qual está ligado à investigação do processo, e ao mesmo tempo aos interesses que movem cada entrevista em específico.

\section{Segundo ato: ação}

Depois de estabelecer o contrato o mediador pode colocar uma questão a fim de criar abertura à evocação de T1. As questões colocadas, no início, meio ou fim da entrevista são de suma importância. Expressões como "que é que", "onde", "como" e "quando" devem ser privilegiadas. O mesmo deve ocorrer com formatos próximos de "Como sabia que era difícil...?”, "Qual delas percebeu que era simples?", "Como reconheceu que era evidente", "O que foi necessário para que você...?”. A intensão é permitir ao artista encontrar informações sobre o que percebeu, sobre como fez.

Contudo, da mesma forma deve-se excluir perguntas que dizem respeito à causalidade das situações, aos pedidos diretos de esclarecimento e, particularmente, aquelas que tendem a surgir espontaneamente, quando o mediador não compreende algum ponto, procurando por explicações. Ou seja, todas as questões que iniciam com um "por que". A razão essencial é que estas perguntas carregam as respostas para fora do domínio da experiência vivenciada, abrindo a entrevista apenas ao domínio da explicação, 
ao Know What. Cabe ao mediador, portanto, evitar cuidadosamente, todo tipo de perguntas que circulem em torno da forma "por que".

\section{Terceiro ato: retomadas}

Durante a entrevista o mediador sentirá necessidade, muitas vezes, de intervir. Essas intercessões podem ser realizadas de quatro maneiras distintas:

1) Inicialização: Aplicável no começo e ou no recomeçar, logo após a interrupção de uma fala. A inicialização pode ser utilizada pelo mediador quando ele pretende introduzir um determinado diálogo. Exemplo: “ainda não falamos sobre teus desenhos, poderias contar um pouco como trabalhas neles?".

2) Focalização: Aplicável em momentos de devaneio, confusão da fala. Algumas estruturas de diálogo acabam caindo em questionamentos, problematizações, fugas conscientes e ou inconscientes da experiência vivida. A focalização pode ser utilizada pelo mediador quando ele precisa buscar, juntamente com o entrevistado, o momento exato, o ponto particular que será objeto de atenção da entrevista. Exemplo: "Compreendo, mas você estava falando sobre a montagem da instalação, quando soube que ela estava pronta?".

3) Elucidação: Aplicável quando a estrutura da conversa já atingiu os níveis exigidos pela inicialização e pela focalização. A elucidação pode ser utilizada pelo mediador para atualizar o desenvolvimento da ação buscando um maior grau de refinamento na narração da experiência. Objetiva-se aqui, sempre levando em conta a ética, um aprofundamento sobre algumas questões levantadas na entrevista. Exemplo: "Esse ponto é mesmo muito interessante. Você poderia contar um pouco mais como foi que chegou a ...”.

4) Regulação: Aplicável em qualquer momento. A regulação pode ser utilizada pelo mediador para estabelecer o início da entrevista, ou, de maneira geral, quando se perdem as condições para o bom andamento dela, deve-se fazer uso da regulação a fim de garantir as condições que permitem a verbalização da ação. Exemplo: "Não se preocupe, isso não é importante. Quem sabe você me conta como foi que encontrou os materiais de que precisava...". 


\section{Quarto ato: fechamento}

Apesar de não haver especificação de Vermesch a respeito deste tópico acreditamos que um bom fechamento seja fundamental. Eticamente falando, talvez seja um dos momentos mais importantes. No fechamento o mediador deve retomar o contrato para demonstrar o que fora realizado, o que haviam combinado, e abrir ao artista um espaço para questões, dúvidas, ansiedades que possam ter sido desencadeadas durante a entrevista. Torna-se importante indagar ao artista o que aprendeu, descobriu, durante a experiência de entrevista.

\section{Uma experiência em processo}

Tentamos problematizar com este ensaio o privilégio que as significações Know What - possuem em detrimento dos fazeres - Know How - nas pesquisas contemporâneas sobre arte. Utilizamos alguns fragmentos de estudos de Francisco Varela com a intenção de tomar a experiência em processos artísticos não como um detalhe subjetivo do artista, e ou do público, mas sim como um conceito chave a um modo particular de pesquisar arte. Acreditamos que a Entrevista de Explicitação, desenvolvida por Vermesch com base nos trabalhos de Varela et.al, possa servir como inspiração à tais pesquisas.
As análises desenvolvidas aqui, entretanto, não pretendem fornecer receitas e ou métodos de trabalho. Mas antes escavar o pensamento em direção à experiência que envolve a arte, procurando por meios de falar dessa experiência de modo a expor o que a compõe, e as potencialidades envolvidas no processo artístico no que diz respeito a essa atenção ao presente.

Dizendo de outra forma, até que ponto a arte que questiona o objeto, legada por Duchamp, numa afronta ao pensamento kantiano acerca da experiência estética, não estaria dando um novo salto, procurando por novos meios de pensar a experiência, não mais a partir do objeto-obra-de-arte, mas do processo, que implicaria também a existência? Assim, acreditamos que procurar por formas de expor esse processo, não mais atravessadas pelos espaços tradicionalmente dados à arte, se faz cada vez mais necessário.

Esta escrita se pôs em movimento num desejo de ficar a espreita destes devires. Gostaríamos de permanecer nesta tensão. Talvez, ninguém melhor que um artista saiba como nos auxiliar nesse sentido: "Por tempo demais o artista foi alienado do seu próprio tempo. Críticos, ao focalizarem o 'objeto de arte', privam o artista de qualquer existência no mundo tanto da mente como da matéria. O processo mental do artista que tem lugar no tempo é desapropriado de 
modo que um valor de mercadoria possa ser mantido por um sistema independente do artista. A arte, nesse sentido, é considerada 'atemporal' ou um produto 'de tempo algum'; isso se torna um modo conveniente de explorar o artista fora de sua justa reinvindicação pelos seus processos temporais. (...) A crítica, dependente de ilusões racionais, apela para uma sociedade que só valoriza arte enquanto mercadoria separada da mente do artista. Separando a arte do 'processo primário' o artista é enganado de mais de uma maneira. As separações de 'coisas', ‘formas', 'objetos', 'figuras', etc.; com começos e fins, são meras ficções convenientes: só há uma ordem de desintegração incerta que transcende os limites das separações racionais. As ficções erigidas na torrente desgastada do tempo são aptas para submergir a qualquer momento." (Smithson, 2009, p. 196)

\section{Referências}

Abramovic, Marina. (2013). Entrevista concedida ao Jornal Folha De São Paulo. Disponível em: < $\underline{\text { http://www1. }}$ folha.uol.com.br/ilustrada/831250-leia-aentrevista-de-marina-abramovic-na-integra.

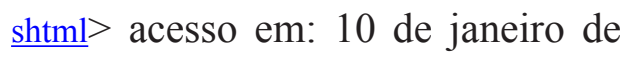
2013.

Agamben, Giorgio. (2005). Infância e história: destruição da experiência e origem da história. Belo horizonte: editora UFMG; 2005. 188p. Tradução de Henrique Burigo.

Bergson, Henri. (1990). Matéria e memória: ensaio sobre a relação do corpo com o espírito. Tradução de Paulo Neves da Silva. São Paulo: Martins Fontes.

Cage, John. (2009). O futuro da música. In: Escritos de Artistas: anos 60/70. Ferreira, Gloria; Cotrim, Cecilia. Rio de janeiro: Editora Jorge Zahar.

De Duve, Thierry. (2004). Reflexões críticas: na cama com madonna. In: desafios para a tarefa crítica. Pradilla, Ileana. Revista Concinnitas número 7. Rio de Janeiro: Editora UERJ.

Varela, Francisco; Thompson, Evan; Rosch, Eleanor. (2003). A mente incorporada: ciências cognitivas e experiencia humana. Porto Alegre: Artmed.

Varejão, Adriana. (2012). Entrevista concedida a Eric Nepomuceno no programa Sangue Latino. Produção de Canal Brasil, TV Cultura e Urca Filmes. Disponível em: $\quad$ http://www.youtube.com/ watch?v=09jwnft9g0g. Acesso em: 19 de novembro de 2012.

Vermesch, Pierre. (1994). L'entretien déxplicitation. Issy-les-moulineaux, esf éditeur. 
Kaprow, Allan. (2009). O legado de Jackson Pollock. In: Escritos de Artistas: anos 60/70. Ferreira, Gloria; Cotrim, Cecilia. Rio de janeiro: Editora Jorge Zahar.

Smithson, Robert. (2009). Uma sedimentação da mente: projetos de terra. In: Escritos de Artistas: anos 60/70. Ferreira, Gloria; Cotrim, Cecilia. Rio de janeiro: Editora Jorge Zahar.

\section{Notas}

1 Aqui cabe uma pequena observação. Não pretendemos veicular que apenas o artista fabrica uma experiência com a arte, justamente porque desejamos explorar também a ideia de Varela de que a experiência pode ser a própria reflexão incorporada, e assim, o espectador, colaborador, enfim, aquele que acessa uma obra de arte, seja um objeto ou uma proposição artística qualquer, também pode fabricar esse modo especial de experiência, se se colocar diante da obra, como sugere Varela, a partir de sua própria perspectiva, tomando como ponto de partida quem ele é (ou está, ou se fabrica) diante da obra, e como ele está se colocando em relação a ela.

${ }^{2}$ Para Varela, Thompson e Rosch (1991) as ciências cognitivas tiveram sua origem no movimento cibernético e receberam aportes Rev. Polis e Psique, 2013;3(2):113-131 de diferentes disciplinas. Além da corrente mais forte, conhecida como cognitivismo, os autores apontam outras perspectivas como a emergência e a enação que trariam alternativas à hipótese cognitivista.

${ }^{3}$ Podemos ver ainda no pensamento de um músico como John Cage, refletindo acerca da "abertura da mente à música", como escreve, esse mesmo reconhecimento a uma interpenetração das culturas no que concerne à arte, como aqui queremos sinalizar: "No século XIX, mesmo entre os ingleses ocupando a Índia, eram poucos e raros os que levavam a música indiana seriamente em consideração. Os tempos mudaram. Atualmente se uma universidade leva a musica seriamente em consideração (...), reúne em uma mesma escola tantas culturas musicais diferentes do mundo todo quanto for possível.” (2009, p. 335)

Lilian Hack: Mestranda pelo Programa de Pós-Graduação em Artes Visuais do Instituto de Artes da UFRGS, sob orientação do professor Dr. Edson de Sousa. Bolsista CAPES. Membro do grupo de pesquisa LAPPAP - Laboratório de Pesquisa em Psicanálise, Arte e Política. Especialista em Arte e Ensino das Artes pela FAP (2010). Graduada em Licenciatura em Artes Visuais pela FURB (2007). Vem desenvolvendo pesquisas que procuram pensar as ressonâncias entre Arte e Linguagem, nos desdobramentos 
que compõe os entrelaçamentos entre arte e vida, na arte contemporânea.

E-mail: 1ilianhack@gmail.com

Édio Raniere: Doutor em Psicologia Social pela Universidade Federal do Rio Grande do Sul. Professor na Universidade Federal de Pelotas. Autor de 'Escrever o Caos com Luz' e 'NuTE: cartografia de um teatro'.

\section{E-mail: edioraniere@gmail.com}

Cleci Maraschin: Professora associada do Instituto de Psicologia da Universidade Fe- deral do Rio Grande do Sul. Sua área de pesquisa inclui a psicologia social, a cognição e as novas tecnologias e seus efeitos na saúde e na educação. Docente e orientadora nos Programas de Pós-Graduação em Psicologia Social e Institucional e em Informática na Educação. Pesquisadora do CNPq.

E-mail: cleci.maraschin@gmail.com 